\title{
Intracoronary pyruvate in cardiogenic shock as an adjunctive therapy to catecholamines and intra-aortic balloon pump shows beneficial effects on hemodynamics
}

\author{
Wolfgang Schillinger • Mark Hünlich • \\ Samuel Sossalla $\cdot$ Hans-Peter Hermann • \\ Gerd Hasenfuss
}

Received: 6 July 2010/Accepted: 16 November 2010/Published online: 4 December 2010

(C) The Author(s) 2010. This article is published with open access at Springerlink.com

\begin{abstract}
Aims Pyruvate was shown to increase cardiac performance in isolated human and animal myocardium and in patients with chronic heart failure. We sought to investigate the effects of pyruvate in acute heart failure.

Methods and results Patients presenting with cardiogenic shock because of acute myocardial infarction were subjected to standard care with primary PCI and intra-aortic balloon pump (IABP). Then, a Swan-Ganz catheter was placed in the pulmonary artery and hemodynamics was analyzed before, during and after intracoronary administration of $300 \mathrm{mmol} / \mathrm{L}$ pyruvate $(360 \mathrm{ml} / \mathrm{h})$. Pyruvate induced a significant increase in cardiac index (CI $2.23 \pm 0.53$ vs. $\left.1.95 \pm 0.45 \mathrm{~L} \mathrm{~min}^{-1} \mathrm{~m}^{-2} ; \quad p<0.05\right)$, stroke volume index (SVI, $29 \pm 6$ vs. $26 \pm 5 \mathrm{~mL} \mathrm{~m}^{-2}$; $p<0.05$ ), and mean systemic arterial pressure (mean SAP, $95 \pm 9$ vs. $87 \pm 9 \mathrm{mmHg} ; p<0.05$ ), whereas heart rate did not significantly change. The effects occurred rapidly within $30 \mathrm{~min}$ and were reversible within $10 \mathrm{~min}$.

Conclusion Intracoronary pyruvate might show beneficial effects in severe acute heart failure in addition to treatment
\end{abstract}

W. Schillinger and M. Hünlich contributed equally.

Trial registration Clinicaltrials.gov Identifier: NCT00604331.

W. Schillinger · M. Hünlich · S. Sossalla · G. Hasenfuss ( $\square)$ Universitätsmedizin Göttingen, Herzzentrum, Kardiologie und Pneumologie, Robert-Koch-Str. 40,

37099 Göttingen, Germany

e-mail: rfaber@med.uni-goettingen.de

H.-P. Hermann

Medizinische Klinik und Kardiologie, Evangelisches

Krankenhaus Bergisch Gladbach gGmbH,

Bergisch Gladbach, Germany with catecholamines and IABP. These effects should be further investigated in randomized controlled trials.

Keywords CARDIAC output - Inotropic agents · Metabolism · Heart failure $\cdot$ Shock
Abbreviations
CABG Coronary artery bypass graft
CI Cardiac index
CO Cardiac output
HR Heart rate
IABP Intra-aortic balloon pump
PAP Pulmonary artery pressure
PCI Percutaneous coronary intervention
PCWP Pulmonary capillary wedge pressure
PVR Pulmonary vascular resistance
RAP Right atrial pressure
SAP Systemic arterial pressure
STEMI ST-segment elevation myocardial infarction
SVI Stroke volume index
SVR Systemic vascular resistance

\section{Introduction}

Cardiogenic shock following myocardial infarction has a poor prognosis with mortality between 40 and 60\% [6]. Prognosis improves with PCI. However, in many cases despite maximum therapy including inotropic agents and IABP cardiac output and blood pressure are not adequate to prevent progressive organ failure. Therefore, new strategies to rapidly improve hemodynamics after PCI are urgently needed. 
It has been suggested recently that pyruvate which is a key intermediate in the glycolytic and pyruvate dehydrogenase pathways shows beneficial hemodynamic effects. The use of different animal species showed that pyruvate exerted positive inotropic effects in vitro [19] and in vivo $[12,13,15,23]$. Similar results were found in isolated multicellular preparations from end-stage failing human hearts [7]. Measuring oxygen consumption by the diffusionmicroelectrode technique in isolated contracting rabbit myocardium, it could be demonstrated that economy of myocardial contraction remained unchanged with pyruvate despite a substantial increase in force-time integral whereas $\beta$-adrenergic stimulation decreased economy [11]. Moreover, pyruvate potentiated the inotropic response of $\beta$-adrenergic stimulation in isolated animal [21] and human myocardium [10]. Previous in vivo studies in patients with chronic compensated heart failure have demonstrated increased $\mathrm{CO}$, improved relaxation and decreased left ventricular filling pressure and $\mathrm{HR}$ with intracoronary pyruvate infusion $[8,9]$.

Thus, pyruvate may have beneficial effects in acute severe heart failure and cardiogenic shock, but no data is currently available directly supporting this hypothesis. We therefore investigated the effects of intracoronary pyruvate infusion in patients with severe circulatory failure due to acute coronary syndrome necessitating pharmacological and mechanical support.

\section{Methods}

\section{Patients}

Patients were eligible for participation if they were presenting with cardiogenic shock because of acute myocardial infarction and if primary PCI could be successfully performed. Cardiogenic shock was defined according to current guidelines [2]. Detailed inclusion and exclusion criteria are given in Table 1. Written informed consent was obtained from patients or close relatives in unconscious patients prior to the study. Alternatively, the study was performed with regard to the patients' presumed will. In the latter ones, written consent was obtained as soon as possible after study termination from patients after having regained consciousness or from close relatives. One patient with presumed anterior wall STEMI at the initial evaluation was excluded from further analyses because continuative evaluation revealed chronic anterior wall aneurysm by echocardiography, absence of rise in troponin $t$, failure of ST segment resolution after successful PCI, and significant decompensated aortic stenosis as the cause of acute cardiac failure. Eight patients were included in the final analyses: one was female and seven were male. The median age was 68 years (range 40-84). All patients were on treatment with catecholamines (epinephrine 0.03-0.34

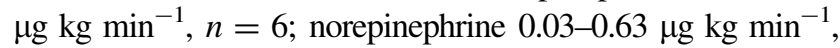
$n=5)$. HR was $89 \pm 18 \mathrm{~min}^{-1}$ and systolic pressure was $92 \pm 8 \mathrm{mmHg}$ (mean $\pm 95 \% \mathrm{CI}$ ). The study was reviewed and approved by the ethical committee of the University Medical Center of Goettingen.

\section{Cardiac catheterization and treatment of myocardial infarction}

Cardiac catheterization, PCI and placement of an IABP were performed according to current guidelines [1, 2, 22]. After termination of PCI the guiding catheter was left in the ostium of the coronary artery. During these interventions all measures were undertaken to obtain stable conditions prior to the study protocol: Catecholamine doses and ventilation conditions were adjusted to obtain sufficient hemodynamics and blood gases. Sedatives and muscle

Table 1 Inclusion and exclusion criteria

\begin{tabular}{|c|c|}
\hline Inclusion criteria & Exclusion criteria \\
\hline Age, $18-85$ years & Failure of PCI or need for CABG \\
\hline Weight, $45-110 \mathrm{~kg}$ & $\begin{array}{l}\text { Cardiogenic shock of other origin than ischemic } \\
\text { (e.g., tamponade, valvular disease, arrhythmogenic) }\end{array}$ \\
\hline Height, $150-195 \mathrm{~cm}$ & $\begin{array}{l}\text { Instability necessitating significant change of conditions } \\
\text { (e.g., catecholamine dose, ventilation) before pyruvate infusion }\end{array}$ \\
\hline Acute myocardial infarction & Failure to insert intra-aortic balloon pump \\
\hline Successful primary PCI & Malignant tumor \\
\hline Cardiogenic shock & Pregnancy or lactation \\
\hline $\begin{array}{l}\text { Need for catecholamines or intra-aortic } \\
\text { balloon pump }\end{array}$ & Poor compliance \\
\hline \multirow{2}{*}{$\begin{array}{l}\text { Stable conditions in hemodynamics, rhythm } \\
\text { and ventilation before pyruvate infusion }\end{array}$} & Alcohol or drug abuse \\
\hline & Participation in concurrent clinical trial \\
\hline
\end{tabular}


relaxants were administered as needed. Bicarbonate was administered to counterbalance acidosis if present. Comatose survivors of cardiac arrest were cooled to $32^{\circ}-34^{\circ} \mathrm{C}$ by infusion of cold $\mathrm{NaCl} 0.9 \%$ solution for reasons of neuroprotection. 150-300 mg of amiodarone was injected if relevant arrhythmias were present. After these measures, all conditions were kept stable.

Measurements of intracoronary pyruvate effects

A 7F Swan-Ganz catheter was placed in the pulmonary artery from a femoral vein. About 30-45 min after having performed all interventions and having gained stable conditions; CI was determined in triplicate by the thermodilution technique and PCWP was measured. After a waiting period of $30 \mathrm{~min}$ in order to assure stable conditions, intracoronary $\mathrm{NaCl} 0.9 \%$ was administered via the guiding catheter with an infusion rate of $360 \mathrm{~mL} / \mathrm{h}$. After $10 \mathrm{~min}$, HR, SAP, RAP, PAP, PCWP, SVI and CI were determined. After these measurements, intracoronary $\mathrm{NaCl} 0.9 \%$ infusion was stopped and intracoronary pyruvate $300 \mathrm{mmol} / \mathrm{L}$ was administered at an identical infusion rate of $360 \mathrm{~mL} / \mathrm{h}$ for $30 \mathrm{~min}$. Every $10 \mathrm{~min}$, hemodynamic measurements were repeated. Then, pyruvate was stopped and intracoronary $\mathrm{NaCl} 0.9 \%(360 \mathrm{~mL} / \mathrm{h})$ was given for another $10 \mathrm{~min}$ followed by final hemodynamic measurements. After termination of measurements, patients were transferred to the intensive care unit, immediately, and subjected to standard treatment.

\section{Statistical analyses}

GraphPad Prizm Version 5 was used for statistical analyses. Previous studies in stable patients with chronic heart failure showed statistically significant effects of intracoronary pyruvate in small numbers of patients $(8,9)$. Because of the expected difficulties in patient recruitment, the study protocol allowed analyses of data after eight patients and termination of the study if statistically significant differences were present. Data are expressed as mean $\pm 95 \%$ confidence interval. Differences between means were tested for statistical significance by 1-way repeated measures ANOVA followed by Newman-Keuls multiple comparison tests. A $p$ value of $<0.05$ was accepted as statistically significant.

\section{Results}

A summary of hemodynamic measurements and pyruvate effects is given in Table 2. Cardiac performance was severely impaired in all patients. Baseline hemodynamics directly before pyruvate were as follows: CI $2.07 \pm 0.47$, HR $76 \pm 8$, SVI $27 \pm 5$, mean $\operatorname{SAP} 93 \pm 7$, mean
Table 2 Hemodynamic effects of intracoronary pyruvate in addition to catecholamines and IABP

\begin{tabular}{|c|c|c|}
\hline $\begin{array}{l}\text { Intervention } \\
\text { (point in time) }\end{array}$ & $\begin{array}{l}\text { Pyruvate } \\
\text { (40 min) }\end{array}$ & $\begin{array}{l}\mathrm{NaCl} 0.9 \% \\
(50 \mathrm{~min})\end{array}$ \\
\hline $\operatorname{HR}\left(\min ^{-1}\right)$ & $76 \pm 9$ & $76 \pm 7$ \\
\hline $\mathrm{CI}\left(\mathrm{L} \min ^{-1} \mathrm{~m}^{-2}\right)$ & $2.23 \pm 0.53$ & $1.95 \pm 0.45^{*}$ \\
\hline SVI $\left(m L m^{-2}\right)$ & $29 \pm 6$ & $26 \pm 5^{*}$ \\
\hline Mean SAP (mmHg) & $95 \pm 9$ & $87 \pm 9$ \\
\hline Mean PAP (mmHg) & $33 \pm 6$ & $31 \pm 4$ \\
\hline Mean PCWP (mmHg) & $23 \pm 7$ & $22 \pm 4$ \\
\hline Mean RAP (mmHg) & $16 \pm 3$ & $16 \pm 3$ \\
\hline SVR (dyn s cm ${ }^{-5}$ ) & $1,608 \pm 354$ & $1,635 \pm 325$ \\
\hline PVR (dyn s cm ${ }^{-5}$ ) & $216 \pm 136$ & $236 \pm 159$ \\
\hline
\end{tabular}

* Means $p<0.05$

PCWP $23 \pm 6$. Continuous intracoronary pyruvate infusion induced an increase in CI that amounted to $2.23 \pm$ $0.53 \mathrm{~L} \mathrm{~min}^{-1} \mathrm{~m}^{-2}$ after $30 \mathrm{~min}$. After intracoronary pyruvate was stopped, CI rapidly dropped down to $1.95 \pm$ $0.45 \mathrm{~L} \mathrm{~min}^{-1} \mathrm{~m}^{-2}$ within $10 \mathrm{~min}(p<0.05$, Fig. 1$)$. Similarly, there was a rise in SVI to $29 \pm 6 \mathrm{~mL} \mathrm{~m}^{-2}$ after 30 min pyruvate. After pyruvate was stopped SVI declined to $26 \pm 5 \mathrm{~mL} \mathrm{~m}^{-2}$ within $10 \min (p<0.05$, Fig. 1$)$. Mean SAP was $95 \pm 9 \mathrm{mmHg}$ after $30 \mathrm{~min}$ of intracoronary pyruvate infusion and decreased to $87 \pm 9 \mathrm{mmHg} 10 \mathrm{~min}$ after pyruvate was stopped (Fig. 1). Even though these effects were not pronounced, an increase in CI, SVI, and mean SAP was clearly found in most patients and differences as a result of the intervention were statistically significant (Fig. 1). By comparing hemodynamics after $30 \mathrm{~min}$ of pyruvate infusion (point in time $40 \mathrm{~min}$ ) to values $10 \mathrm{~min}$ after cessation (point in time $50 \mathrm{~min}$ ), we calculated a net positive pyruvate effect of $15 \pm 5 \%$ on CI, of $16 \pm 5 \%$ on SVI, and of $10 \pm 8 \%$ on mean SAP in addition to catecholamine treatment and mechanical support by IABP. CI, SVI, and mean SAP tended to drop after termination of pyruvate infusion as compared to baseline values; however, neither of these changes was statistically significant. In parallel to changes in CI, SVI, and mean SAP, there was a tendency for a drop in SVR and PVR under the influence of pyruvate. Yet, these changes were not statistically significant as well. Pyruvate did not induce significant changes in HR, mean PCWP, mean RAP, and mean PAP (Table 2).

\section{Discussion}

The present study shows that intracoronary pyruvate has positive inotropic effects in patients with cardiogenic shock despite medical treatment with catecholamines and 

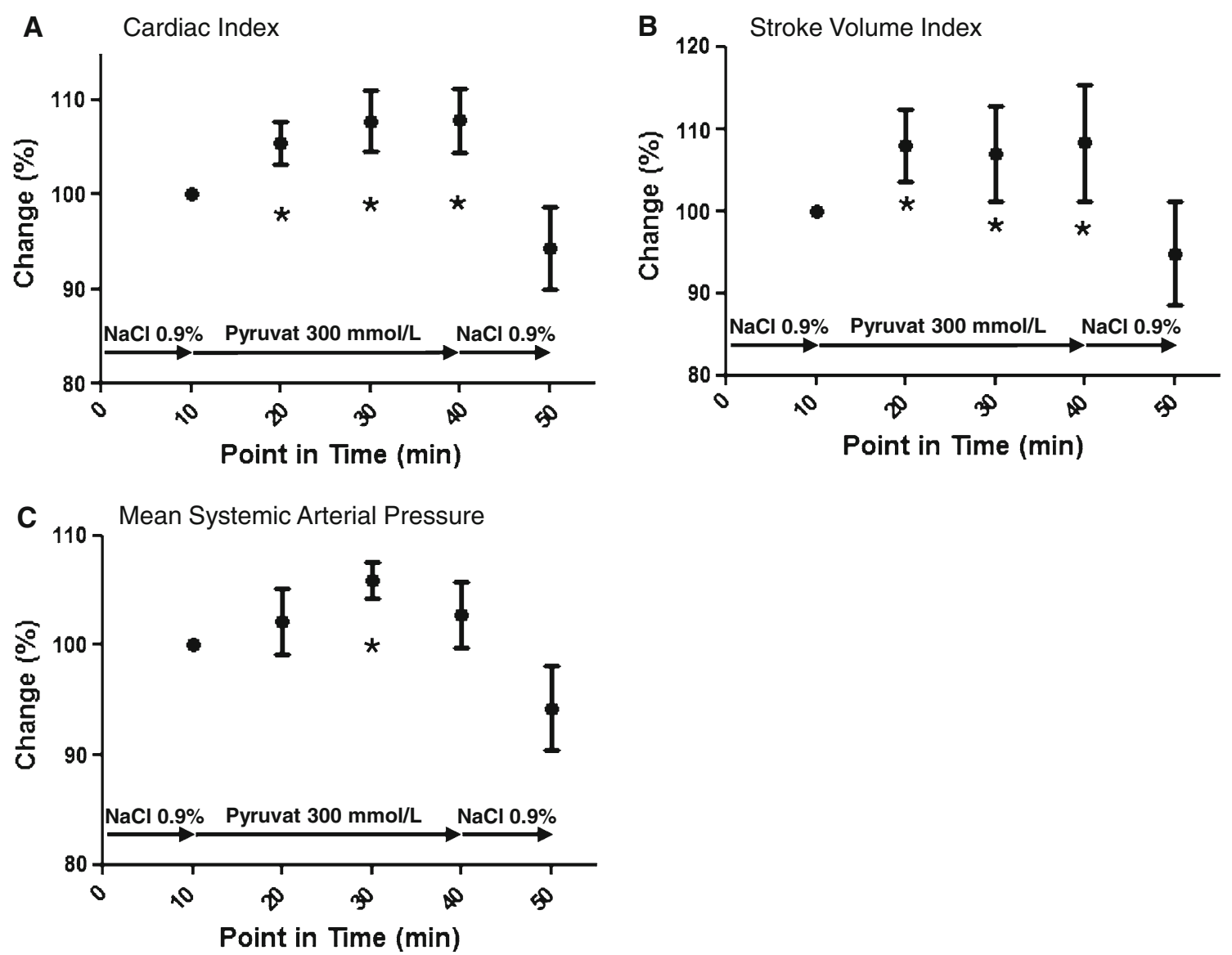

Fig. 1 Graphs showing changes in CI (a), SVI (b), and mean SAP (c) under the influence of $\mathrm{NaCl} 0.9 \%$ and pyruvate $300 \mathrm{mmol} / \mathrm{L}$ at different points in time. Interventions are indicated by arrows. There was a significant effect of pyruvate on each hemodynamic parameter

mechanical support by IABP. We found an increase in CI and SVI by $15 \pm 5$ and $16 \pm 5 \%$, respectively, as an effect of pyruvate that was not secondary to increases in HR. Moreover, mean SAP was increased by $10 \pm 8 \%$. All other conditions were kept stable during pyruvate infusion and no significant differences of any hemodynamic parameter were detected between values at baseline and after complete reversal of pyruvate effects. Thus, these effects cannot be attributed to standard interventions related to treatment of myocardial infarction and cardiogenic shock or to changes in hemodynamics other than that caused by intracoronary pyruvate.

In a previous study, we could show that the observed beneficial effects of pyruvate on hemodynamics mainly resulted from direct myocardial effects and not from altered loading conditions because intracoronary pyruvate was almost completely extracted from the coronary circulation by the myocardium and did not induce systemic vasodilatation [9]. Furthermore, it was shown that pyruvate does not induce coronary vasodilatation [4]. The underlying mechanisms of pyruvate on the myocardium have been

as calculated by repeated measures ANOVA. *Means $p<0.05$ versus $50 \mathrm{~min}$. Neither of all parameters showed significant differences at $50 \mathrm{~min}$ as compared to $10 \mathrm{~min}$ indicating stable hemodynamics at baseline

extensively investigated in animal and human myocardium $[4,7,10,12-15,19,21,23]$. It was demonstrated that pyruvate increases the energetic stimulation of the sarcoplasmic reticulum calcium pump due to an increase in phosphorylation potential with enhanced free energy of ATP hydrolysis [4, 19]. This promotes relaxation of the myofilaments and also results in enhanced calcium content of the sarcoplasmic reticulum, which in turn results in more calcium available for systolic release and activation of contractile proteins $[5,7]$. In addition, it was shown that pyruvate increases intracellular $\mathrm{pH}$ which may partly result from uptake of pyruvate and protons into the mitochondria by the monocarboxylate-proton symporter [7, 17]. The increase in intracellular $\mathrm{pH}$ leads to an enhanced calcium sensitivity of contractile proteins and force development [3].

These effects on the cellular and molecular level had been previously shown to translate into pronounced beneficial effects on systolic and diastolic cardiac performance in patients with chronic heart failure. In a previous study in patients with chronic stable heart failure, pyruvate 
increased cardiac index without increasing $\operatorname{HR}[8,9]$. These findings resulted from an increase in left ventricular ejection fraction [8]. Moreover, positive effects on maximum rate of left ventricular isovolumic pressure rise were found by use of a micromanometer catheter [8]. Interestingly, in the present study pyruvate exhibited beneficial effects on systolic cardiac performance in acute heart failure ancillary to IABP. IABP was suggested to increase left ventricular ejection fraction and CO [16]. With regard to diastolic function, the previous studies in chronic heart failure demonstrated that pyruvate decreased PCWP [9] and left ventricular end-diastolic pressure [8]. Contrasting these findings, the effects of pyruvate on left ventricular filling pressure as measured by PCWP were absent in the present study. This lack of an unloading effect of pyruvate might be secondary to the action of IABP which induces a pronounced systolic unloading of the heart [16] implying that potential effects of pyruvate on left ventricular preload might be masked by IABP. It is of note that the role of IABP in acute ischemic shock was recently questioned $[18,20]$. The present study was designed and conducted in consideration of current guidelines that strongly recommend IABP in acute myocardial infarction complicated by shock [1, 22]. However, the evidence supporting this recommendation is rather limited. Thus, investigation of the effects of intracoronary pyruvate in acute heart failure without IABP might be mandatory.

After termination of pyruvate, CI, SVI, and mean SAP tended to drop below the baseline values. These changes were not statistically significant. However, examination of this phenomenon in further studies might be worthwhile in order to prevent a worse outcome due to sudden termination of therapy. The major shortcoming of pyruvate is the necessity of intracoronary application. Because it is rapidly metabolized and the hemodynamic effect requires doses above $1 \mathrm{mM}$ very high doses would be necessary if it was administered intravenously. Such high doses, however, would lead to sodium overload and hyperosmolarity if the sodium salt of pyruvic acid was used as in the present study. However, in specialized centers with invasive facilities the intracoronary route might be an option for patients with cardiogenic shock refractory to standard care. Moreover, these problems may be overcome by the development of novel formulations such as the choline salt.

In summary, pyruvate might have the potential of a favorable agent in acute heart failure and might serve as an adjunctive therapy to catecholamines. It might save catecholamines that are potentially harmful. Moreover, the effects of pyruvate might especially help in acute ischemic heart failure because the inotropic effects of pyruvate occurred without worsening of myocardial economy. These potentially beneficial effects of pyruvate should be investigated in randomized controlled trials.
Open Access This article is distributed under the terms of the Creative Commons Attribution Noncommercial License which permits any noncommercial use, distribution, and reproduction in any medium, provided the original author(s) and source are credited.

\section{References}

1. Antman EM, Anbe DT, Armstrong PW, Bates ER, Green LA, Hand M, Hochman JS, Krumholz HM, Kushner FG, Lamas GA, Mullany CJ, Ornato JP, Pearle DL, Sloan MA, Smith SC Jr (2004) ACC/AHA guidelines for the management of patients with ST-elevation myocardial infarction-executive summary: a report of the American College of Cardiology/American Heart Association Task Force on Practice Guidelines (Writing Committee to Revise the 1999 Guidelines for the Management of Patients With Acute Myocardial Infarction). Can J Cardiol 20:977-1025

2. Bassand JP, Hamm CW, Ardissino D, Boersma E, Budaj A, Fernandez-Aviles F, Fox KA, Hasdai D, Ohman EM, Wallentin L, Wijns W (2007) Guidelines for the diagnosis and treatment of non-ST-segment elevation acute coronary syndromes. Eur Heart J 28:1598-1660

3. Bers DM (2001) Excitation-contraction coupling and cardiac contractile force. Kluwer, Dordrecht

4. Bunger R, Haddy FJ, Querengasser A, Gerlach E (1975) An isolated guinea pig heart preparation with in vivo like features. Pflugers Arch 353:317-326

5. Chen W, London R, Murphy E, Steenbergen C (1998) Regulation of the $\mathrm{Ca} 2+$ gradient across the sarcoplasmic reticulum in perfused rabbit heart. A 19F nuclear magnetic resonance study. Circ Res 83:898-907

6. Dhalla AK, Wang WQ, Dow J, Shryock JC, Belardinelli L, Bhandari A, Kloner RA (2009) Ranolazine, an antianginal agent, markedly reduces ventricular arrhythmias induced by ischemia and ischemia-reperfusion. Am J Physiol Heart Circ Physiol 297(5):H1923-H1929

7. Hasenfuss G, Maier LS, Hermann HP, Luers C, Hunlich M, Zeitz O, Janssen PM, Pieske B (2002) Influence of pyruvate on contractile performance and $\mathrm{Ca}(2+)$ cycling in isolated failing human myocardium. Circulation 105:194-199

8. Hermann HP, Arp J, Pieske B, Kogler H, Baron S, Janssen PM, Hasenfuss G (2004) Improved systolic and diastolic myocardial function with intracoronary pyruvate in patients with congestive heart failure. Eur J Heart Fail 6:213-218

9. Hermann HP, Pieske B, Schwarzmuller E, Keul J, Just H, Hasenfuss G (1999) Haemodynamic effects of intracoronary pyruvate in patients with congestive heart failure: an open study. Lancet 353:1321-1323

10. Hermann HP, Zeitz O, Keweloh B, Hasenfuss G, Janssen PM (2000) Pyruvate potentiates inotropic effects of isoproterenol and $\mathrm{Ca}(2+)$ in rabbit cardiac muscle preparations. Am J Physiol Heart Circ Physiol 279:H702-H708

11. Keweloh B, Janssen PM, Siegel U, Datz N, Zeitz O, Hermann HP (2007) Influence of pyruvate on economy of contraction in isolated rabbit myocardium. Eur J Heart Fail 9:754-761

12. Liedtke AJ, Nellis SH (1978) Effects of buffered pyruvate on regional cardiac function in moderate, short-term ischemia in swine heart. Circ Res 43:189-199

13. Liedtke AJ, Nellis SH, Neely JR, Hughes HC (1976) Effects of treatment with pyruvate and tromethamine in experimental myocardial ischemia. Circ Res 39:378-387

14. Martin BJ, Valdivia HH, Bunger R, Lasley RD, Mentzer RM Jr (1998) Pyruvate augments calcium transients and cell shortening in rat ventricular myocytes. Am J Physiol 274:H8-H17 
15. Mentzer RM Jr, Van Wylen DG, Sodhi J, Weiss RJ, Lasley RD, Willis J, Bunger R, Habil Flint LM (1989) Effect of pyruvate on regional ventricular function in normal and stunned myocardium. Ann Surg 209:629-633 (discussion 633-624)

16. Parissis $H$ (2007) Haemodynamic effects of the use of the intraaortic balloon pump. Hell J Cardiol 48:346-351

17. Poole RC, Halestrap AP (1993) Transport of lactate and other monocarboxylates across mammalian plasma membranes. Am J Physiol 264:C761-C782

18. Prondzinsky R, Lemm H, Swyter M, Wegener N, Unverzagt S, Carter JM, Russ M, Schlitt A, Buerke U, Christoph A, Schmidt H, Winkler M, Thiery J, Werdan K, Buerke M (2010) Intra-aortic balloon counterpulsation in patients with acute myocardial infarction complicated by cardiogenic shock: the prospective, randomized IABP SHOCK Trial for attenuation of multiorgan dysfunction syndrome. Crit Care Med 38:152-160

19. Scholz TD, Laughlin MR, Balaban RS, Kupriyanov VV, Heineman FW (1995) Effect of substrate on mitochondrial $\mathrm{NADH}$, cytosolic redox state, and phosphorylated compounds in isolated hearts. Am J Physiol 268:H82-H91

20. Sjauw KD, Engstrom AE, Vis MM, van der Schaaf RJ, Baan J Jr, Koch KT, de Winter RJ, Piek JJ, Tijssen JG, Henriques JP (2009) A systematic review and meta-analysis of intra-aortic balloon pump therapy in ST-elevation myocardial infarction: should we change the guidelines? Eur Heart J 30:459-468

21. Tejero-Taldo MI, Sun J, Caffrey JL, Mallet RT (1998) Pyruvate potentiates beta-adrenergic inotropism of stunned guinea-pig myocardium. J Mol Cell Cardiol 30:2327-2339

22. Van de Werf F, Bax J, Betriu A, Blomstrom-Lundqvist C, Crea F, Falk V, Filippatos G, Fox K, Huber K, Kastrati A, Rosengren A, Steg PG, Tubaro M, Verheugt F, Weidinger F, Weis M, Vahanian A, Camm J, De Caterina R, Dean V, Dickstein K, Filippatos G, Funck-Brentano C, Hellemans I, Kristensen SD, McGregor K, Sechtem U, Silber S, Tendera M, Widimsky P, Zamorano JL, Silber S, Aguirre FV, Al-Attar N, Alegria E, Andreotti F, Benzer W, Breithardt O, Danchin N, Di Mario C, Dudek D, Gulba D, Halvorsen S, Kaufmann P, Kornowski R, Lip GY, Rutten F (2008) Management of acute myocardial infarction in patients presenting with persistent ST-segment elevation: the Task Force on the Management of ST-Segment Elevation Acute Myocardial Infarction of the European Society of Cardiology. Eur Heart J 29:2909-2945

23. Yanos J, Patti MJ, Stanko RT (1994) Hemodynamic effects of intravenous pyruvate in the intact, anesthetized dog. Crit Care Med 22:844-850 